\title{
Combustion of Spherically Shaped Large Wood Char
}

\section{Particles}

\author{
Henry Molintas ${ }^{\dagger}$ and A. K. Gupta ${ }^{*}$ \\ Combustion laboratory, Department of Mechanical Engineering, University of
}

\author{
Maryland College Park, MD 20742 \\ †Graduate Student; E-mail: molintas@umd.edu \\ *Corresponding author; E-mail: akgupta@umd.edu
}

\begin{abstract}
\end{abstract}
This paper examines the effects of temperature and oxygen enrichment on

10 conversion of large wood char particle under non-isothermal conditions.

Combustion air and its combination with oxygen are examined at temperatures of 800 and $850^{\circ} \mathrm{C}$ for identical initial char weight, diameter and reaction time. Onefilm ash segregated core and random pore models are used to characterize the combustion condition. The combustion regimes for these particles are found to be

15 near kinetic-diffusion controlled based on the ash segregated core model. Diffusion and reaction rate relationships are also characterized. Oxygen enriched conditions provided greater reactivity as compared to non-enriched oxidation conditions. For the ash segregated core model, the lowest and highest estimated activation energy values are $123 \mathrm{~kJ} / \mathrm{mol}$ and $180 \mathrm{~kJ} / \mathrm{mol}$, respectively. The activation energies obtained with the random pore model showed inconsistencies. Thiele modulus values varied from 500 to 1000 , indicating that the surface reaction rates are significantly faster than pore diffusion rates with oxygen being mostly consumed at the particle surface.

25 Keywords: char, kinetic parameters, ash segregated core model, random pore model, diffusion 


\subsection{Introduction}

The increased global awareness of dwindling energy resources and consequent damaging effects of climate change have prompted scientists and engineers worldwide to consider a far-reaching approach in developing alternative and renewable energy

5 resources [1]. This approach was envisioned for urgency to accelerate global collaborative research efforts to develop energy sources and seek sustainability for the ever increasing global energy demand during this millennium while also conserving the environment.

Presently, coal is a major fossil fuel energy resource in the United States

10 because it is abundant with several hundred years of reserves. However, the environmental damage caused by massive coal mining via open pit and underground operations are considered destructive to groundwater resources and natural habitat. Burning coal in power plants is also known to produce high levels of $\mathrm{CO}_{2}, \mathrm{NOx}$ and other hazardous gases, especially sulfur oxides. Therefore, renewable energy resources

15 such as biomass fuels and municipal solid wastes have captured the interest of researchers worldwide because these have significantly lower adverse impacts on the environment as compared to coal and other fossil fuels.

Commercialization of large scale biomass and municipal solid waste (nonhazardous biomass-based) combustion and gasification technology with processing

20 scales up to 1000 tons/day is currently being investigated [2]. However, large scale biomass energy systems compete directly with food crops production and industrial operations for dedicated and enormous land resources [3]. For countries with limited land areas, such as Japan and the Philippines, real estate is a premium. Hence, small scale energy systems (with processing rates of less than $3000 \mathrm{~kg} /$ day) are considered

25 more reasonable strategy in increasing future biomass energy global energy portfolio than large scale systems. Small scale systems are also ideal in special applications, such as ships [4] and other isolated, remote and space limited areas where decentralized and small scale energy generation could be beneficial. However, the efficiency of small 
scale biomass and solid waste energy processors needs to be enhanced for their greater acceptability as alternative energy resources to coal and other fossil fuels.

Depending on the type of gasifier or combustor, biomass or solid waste fuels are processed with various particle sizes, ranging from $100 \mu \mathrm{m}$ to $100 \mathrm{~mm}[5,6]$.

5 However, biomass and solid waste particles sizes are usually larger than pulverized coal char particles. For updraft or downdraft packed bed processors, biomass fuel size particles are used between 2 to $100 \mathrm{~mm}$ either as received or with some preprocessing to reduce the size [5]. In fluidized-bed systems, biomass fuels are pelletized between 2 to $10 \mathrm{~mm}$, depending on fluidization conditions [6]. However, because kinetic and

10 design parameters for large particles greater than $1 \mathrm{~mm}$ are scarce, gasifiers or combustors are normally oversized to compensate for operational challenges. Also, these trial and error design methods are expensive. Although it is well known that large char particle combustion processes are affected by diffusional effects, accurate kinetic parameters are not available in the open literature. As a result, a previous study

15 conducted on the overall conversion of a large biomass feedstock particle up to $15 \mathrm{~mm}$ showed that actual particle surface temperatures and conversion times were significantly greater than predicted values $[7,8]$. One of the reasons for these deviations is that the kinetic data used in modeling was for small particles (less than $0.25 \mathrm{~mm}$ diameter). Additionally, there is a dearth of experimental data regarding large particle

20 combustion processes but the relative diffusion and kinetic rate relationships are lacking.

This paper is focused on providing kinetic data for large oakwood char particle combustion. Four cases are experimentally investigated using air and $\mathrm{O}_{2}$ enriched air at 800 and $850{ }^{\circ} \mathrm{C}$. Existing mathematical models from the literature are used to evaluate 25 the apparent activation energy, frequency factor, energy released and peak energy rates using Euler Explicit Method via discrete time periods. A linear fit approach was used to evaluate the activation energy and frequency factor from the Arrhenius equation. Char surface temperatures are calculated by considering particle weight and diameter 
evolution with respect to time using a simplified energy equation for a one-film ash segregated core model (ASCM). The ASCM is also used to compare the relative external reaction and diffusional rates of combustion and determine the combustion regime under the specific test conditions. Thiele analysis and random pore model are also used to examine particle surface reaction, pore diffusion rates and internal kinetic parameters. Experimental data are characterized and optimized using non-linear regression method, which enabled data-fitting into the different combustion models examined for the effects of:

a. Effect of $\mathrm{O}_{2}$ enriched air and initial temperatures on conversion

10 b. Characterize relationships between external reaction, external diffusion and pore diffusion rates via the ASCM and random pore model (RPM) and Thiele analysis

c. Effects of other combustion parameters on activation energies

\subsection{Background}

Drying is a first step of the overall conversion process of biomass feedstocks and this involves the interplay of three phases where the liquid and gas travel in solid surfaces through complex pore networks with various sizes and shapes. After particle drying, (above $100{ }^{\circ} \mathrm{C}$ ), feedstock devolatilization or pyrolysis commences, wherein tars containing thousands of compounds including, aromatics and other high molecular weight substances are released [9]. Char reduction (gasification, combustion or their combination) takes over immediately after the devolatilization period, which is the longest step or rate-determining in the overall char reduction or conversion [10]. Although these processes could overlap, these occur nearly in series for batch mode feeding because foregoing processes will be more severe than previous ones, depending

25 on reactor temperature conditions and moisture content, porosity, shape, composition, ash content and size of the feedstock. Char reduction is also influenced by multicomponent diffusion of reactants and products as well as energy transport processes across the external and internal boundary layers of particles. However, 
drying, devolatilization and reduction are generally more intense for large char particles than small particles, less than $0.25 \mathrm{~mm}$. Also, for large particles, these processes are complicated because there is a significant interplay between mass transfer, chemical reaction and heat transfer processes. For small particles less than $0.25 \mathrm{~mm}$, extensive studies have been provided on the relative controlling mechanisms under pure kinetic rate controlled conditions $[11,12]$. However, very few studies have been completed in characterizing the reaction rates and internal or external diffusional rates for large char particles greater than $1 \mathrm{~mm}$. Experimental data are not available for large char particle combustion wherein temporal evolution of particle weights at defined temperatures are

10 established

Currently, there are three operating regimes that are used to describe char reduction phenomena: (a) kinetic controlled or Zone I, (b) diffusion-kinetic controlled or Zone II and (c) diffusion controlled or Zone III [13]. Successful design and development of combustors require accurate understanding of char oxidation regimes

15 and apparent kinetic parameters under various temperatures and oxidizing conditions. Consequently, for large char particles, mathematical modeling need to be more detailed and representative than state-of-the-art models as used mostly for small particle combustion such as the one-step global reaction rate model [13]. Therefore, the combustion behavior, operating regimes and kinetic parameters (activation energy and

20 frequency factor) are examined here in this paper for large char particles. Oakwood char particles between 6.7 to $6.9 \mathrm{~mm}$ are used as char samples. These particle sizes are favorable for compact gasifiers and combustors with space limitations as they alleviate any preprocessing or pulverizing.

\subsection{Experimental Approach}

\section{3.1. Char Material}

The fresh spherical oakwood and its charred particle are shown in Figure 1a and $1 \mathrm{~b}$, respectively. Char samples were made from spherical oakwood samples (see Figure 1a). As reported in literature, the ultimate analysis of oakwood is $6.2 \% \mathrm{H}, 50.2$ 
$\% \mathrm{C}, 43.5 \% \mathrm{O}$ and $0.1 \% \mathrm{~N}$ [14]. The spherical oakwood char particles were pyrolyzed using an electric furnace under isothermal operating conditions at $230{ }^{\circ} \mathrm{C}$ for 24 hours. Char sample preparations and pyrolysis conditions were uniform and identical, having an average volume reduction of $28.4 \%$ from its initial size at $9.5 \mathrm{~mm}$ (see Figure 1).

5 Therefore, the char sample particles and their inherent char porous structures are expected to be nearly consistent and identical in this study.

\subsection{Experimental Procedure}

A schematic diagram of the experimental facility shown in Figure 2 consists of a precision weighing scale, a propane fired reactor, lenses to perform particle imaging,

10 a light source and a high speed camera. The weighing scale was mounted on rigid aluminum structure, which was resiliently mounted on the floor to mitigate and absorb the effects of any external weight disturbances around the vicinity of the experimental facility. The test matrix for this study is shown in Table 1. The Reynolds numbers were calculated based on the initial reactor temperatures and particle diameters. Experiments

15 were performed by first measuring and recording the initial weight and diameter of char particles to be combusted. These particles were tethered to a stainless steel wire connected to the weighing scale to measure the rate of weight loss. Subsequently, these particles were lowered into the reactor zone immediately when the desired oxidizing agents and reactor temperature are established. A data acquisition system was used to

20 record the temperatures and weight measurements every 5 seconds. Particle diameters were also monitored and recorded during combustion via imaging photography every 5 seconds. All measurements were completed after a total reaction time of 40 seconds, the total time when majority of combusted particles fragments and then disintegrates into smaller particles.

\section{$25 \quad 4.0$ Particle Modeling and Analysis}

Two models are used in this study to characterize the kinetic parameters and combustion regimes. These are the one-film ASCM [13] and the random pore model (RPM) [15]. The ASCM characterizes the combustion regimes as well as the relative 
effects of the reaction and diffusion rates at external surface of the particle. This model is also used to estimate the external activation energy based on the calculated surface temperature and observed particle weight loss at discrete time periods. The ASCM assumes a one-film condition (i.e., no flame exists at the boundary layer and that the

$5 \mathrm{CO}_{2}$ gases are formed and released directly from the char external surface) and most of the combustion process is assumed to occur at the particle surface. The changes in activation energies, surface char temperatures, resistances of the governing external chemical reaction and diffusion rates with time are estimated by applying Euler Explicit Method at discrete time periods. This numerical scheme allows one to determine char

10 combustion regimes as well as kinetic and diffusional effects at every discrete time period of interest for the entire combustion period. Time dependent char surface temperatures were also calculated by considering the measured particle weight and diameter to follow a non-linear regression trend to achieve a stable solution of combustion variables via the Euler Explicit numerical method.

15 The other modeling method was the random pore model (RPM) which considers the evolution of internal surface area of a porous char during combustion. Using the established empirical formulation developed by Bhatia et al. [15], the RPM assumes that most of the combustion processes occur at the pores. The pore structural parameter was used to estimate the change in specific surface area as a result of the

20 destruction of the pores during combustion. The calculated activation energies obtained with the RPM were also based on char surface temperatures and structural parameter. However, the RPM does not consider pore fragmentation with the structural parameter as it was assumed constant during combustion.

Thiele analysis was also performed to characterize the ratio of the external 25 reaction rates to pore diffusion rates. This analysis was also extended in estimate the ratio of observed reaction rates to maximum reaction rates (also known as effectiveness factors).

\subsection{One-Film Ash Segregated Core Model for Spherical Particles}


The gasification and combustion of char particles are considered heterogeneous reactions where the reactants exist both in solid and gaseous states. Generally, these reactions are subdivided into the following [13]:

a. Transport of the reactant molecule (e.g. $\mathrm{O}_{2}$, air, $\mathrm{H}_{2} \mathrm{O}$ or $\mathrm{CO}_{2}$ ) to the solid surface either by convection and/or diffusion

b. Adsorption of the reactant molecule at the solid surface

c. Elementary reaction steps, involving various combinations of adsorbed molecules at the solid surfaces with gas-phase molecules

d. Desorption of product molecules from the solid surface

10 e. Transport of the product molecules away from the surface by convection and/or diffusion

Among these processes, (a) and (e) can be analyzed using mass transfer concepts. The intervening steps are more complicated, especially the step process (c). Step process (b) can be analyzed depending on how strongly or weakly the reactant gas 15 molecules are adsorbed at the solid surfaces.

The one-film (no flame at the boundary layer) assumption provides a simplified model enabling the characterization of the kinetic parameters, evolution of char surface temperatures and effects of diffusion during char combustion. A spherically-shaped char particle was considered for this study. The assumptions used in 20 the one-film diffusion-kinetic model for single char particles were [13]:

a. The solid carbon surface burns in quiescent medium such that the effects of convection are ignored because the Reynolds numbers are small.

b. At the particle surface, carbon char reacts kinetically with reactant molecule $\left(\mathrm{O}_{2}\right)$.

25 c. The reactant molecules $\left(\mathrm{O}_{2}\right)$ are weakly adsorbed on the char surface, which means that the equation $\mathrm{d}[\mathrm{Char}] / \mathrm{dt}=\mathrm{k}(\mathrm{T})\left[\mathrm{O}_{2}\right]$ governs during combustion. 
d. The gas phase consists of only $\mathrm{O}_{2}$ and $\mathrm{CO}_{2}$ under combustion conditions. The $\mathrm{O}_{2}$ diffuses inward and reacts with the carbon surface to form $\mathrm{CO}_{2}$ gas which diffuses outward.

e. The carbon internal surface is impervious to gas-species and intra-particle gas diffusion is ignored.

f. The carbon surface temperatures are calculated based on blackbody particle and steady-state process. The heat conduction into the particle interior is assumed to be negligible.

g. No flame exists at the boundary layer. Although the measured or observed weights and particle diameters change sometimes unsteadily due to experimental noises, experimental results are filtered using nonlinear regression on the experimental data to stabilize surface temperature calculations, to estimate the kinetic parameters. Parameters, such as, activation energies, frequency factors, char surface temperatures, the resistances of external

15 diffusion and kinetic rates are also calculated using unity order of reaction via one-step global reaction-diffusion model for mathematically expediency. Under these assumptions, the following governing equation is used to estimate the kinetic parameters for spherically-shaped particles via the one-film ASCM [13]:

$$
\dot{m}_{C}=\frac{Y_{O x, \infty}}{\frac{v+Y_{O x, S}}{\rho D 4 \pi r}+\frac{v \times R_{u} T_{S} \times \exp \left[\frac{E_{a}}{R_{u} T_{S}}\right]}{4 \pi r^{2} \times A \times P \times M W_{\text {mix }}}}
$$

Eq. 1

20 Equation (1) assumes that the overall char burning rate follows an electrical current flow. With this analogy, if the two resistors are considered to be connected in series, two char combustion rate resistances can be described as follows for diffusion and kinetic, respectively:

$R_{\text {diff }}=\frac{v+Y_{O x, S}}{\rho D 4 \pi r}$ Eq. 2

$25 \quad R_{k i n}=\frac{v \times R_{u} T_{s} \times \exp \left[\frac{E_{a}}{R_{u} T_{S}}\right]}{4 \pi r^{2} \times A \times P \times M W_{\text {mix }}}$ Eq. 3 
The ratio of $R_{\text {kin }}$ to $R_{\text {diff }}$ provides a convenient way of determining when the reduction is externally diffusion-controlled or kinetically-controlled, i.e., $R_{\text {kin }} / R_{\text {diff }}<<1$ (Zone III) and $\mathrm{R}_{\text {kin }} / \mathrm{R}_{\text {diff }}>>1$ (Zone I), respectively [13]. When the ratio is near unity, this is considered kinetic-diffusion controlled or Zone II regime.

\section{4.2. Random Pore Model and Thiele Analysis for Spherical Particles}

The one-film ASCM allows a straightforward determination of the combustion regimes (i.e., Zones I, II and III) only at the external surface. For this reason, an additional consideration of the pore surface reactions is needed to determine internal kinetic parameters via the random pore model (RPM). Also, direct calculation of

10 additional parameters such as Thiele modulus, effectiveness factors and the relative changes in the internal specific surface areas per unit weight of char is considered. The RPM is used for a given structural parameter to account for the randomly growing and overlapping pore surfaces as char combustion progresses. This model has been used in analyzing char combustion for micrometer sized particles [15]. The RPM of Bhatia et

15 al. [15] is extensively used to describe the internal reactions of porous particles as shown in equation (4 and 5):

$\frac{d X}{d t}=k_{o} \exp \left(\frac{-E_{a}}{R_{u} T_{s}}\right)(1-X)[1-\varphi \ln (1-X)]^{\frac{1}{2}} \quad$ Eq. 4

With the use of a scanning microscope and the Brunauer-Emmett-Teller (BET) theory, the structural parameter $(\varphi)$ is calculated using equation (5) in terms of the untreated 20 pore structure under initial conditions:

$\varphi=\frac{4 \pi L_{0}\left(1-\theta_{0}\right)}{\left(\rho_{0} S_{g c, 0}\right)^{2}}$

Eq. 5

For a given initial internal specific surface area per unit mass, the internal activation energy of char combustion processes have been calculated using equations (4) and (5) based on char surface temperatures and degree of conversion with respect to time.

25 Although char porosity model calculations are still under development, the internal specific surface area is assumed to be influenced by the extent of conversion and pore 
structural parameter [15]. The following assumptions are used while considering the random pore model during char combustion:

a. Network pores are considered overlapping and randomly growing during reactions, which can either increase (i.e., pore size increases, exposing more surface area to be oxidized) or decrease (i.e., confined fragmentation can inhibit internal reaction) the area available for reaction.

b. The effect of oxidant convection into the particle is ignored.

c. Because the experiment is conducted at very high air-to-fuel oxidation ratios, carbon char reacts kinetically with $\mathrm{O}_{2}$ in air and $\mathrm{CO}_{2}$ is produced.

d. $\mathrm{O}_{2}$ and $\mathrm{CO}_{2}$ are weakly adsorbed at the internal char surfaces, which means $\mathrm{d}[\mathrm{Char}] / \mathrm{dt}=\mathrm{k}(\mathrm{T})\left[\mathrm{O}_{2}\right]$ governs.

e. The gas phase consists of only $\mathrm{O}_{2}, \mathrm{CO}_{2}$ and inert gas $\left(\mathrm{N}_{2}\right)$. The $\mathrm{O}_{2}$ diffuses inward and reacts with the internal char surface to form $\mathrm{CO}_{2}$, which diffuses outward.

15 f. The spherically-shaped carbon internal surface is porous and the oxidants react with the internal surfaces.

g. The spherically-shaped carbon surface temperatures are calculated based on a blackbody particle, using steady-state energy process and the heat conduction into the particle interior is neglected.

20 In order to understand the relationship between external surface reactions and pore diffusion within the particle, Thiele modulus (Ø) (a dimensionless number), is used to calculate the effectiveness factor $[16,17]$. This compares the external reaction rates to internal or pore diffusion rates. When $\varnothing<<1$, the chemical reaction rates are slow as compared to the internal or pore diffusion rates; however, when $\varnothing>>1$, the 25 chemical reaction rates are much faster than the internal diffusion rates during char combustion. Hence, for a first order of reaction with a spherical char under $\mathrm{C}+\mathrm{O}_{2}$ $\rightarrow \mathrm{CO}_{2}$ reaction, the Thiele modulus formulation in terms of the weight burning flux was derived as shown in equation (6) [17]: 
$\emptyset=r \sqrt{\frac{v \ddot{m}_{c} \rho_{c} S_{g c}}{D_{e f f}\left[O_{o x, s}\right] M W_{o x}}}$

Eq. 6

As shown in equation $(7)$, the initial specific surface area $\left(\mathrm{S}_{\mathrm{gc}, 0}\right)$ per unit mass is postulated to change with the degree of char conversion where " $k$ " and " 0 " subscripts represent time and initial conditions, respectively. This formulation [15] is

5 provided below in equation (7):

$$
\begin{array}{ll}
S_{g c, k}=S_{g c, 0} \sqrt{1-\varphi \ln \left(1-X_{k}\right)} \quad \text { Eq, } 7
\end{array}
$$

The initial char particle specific surface area $\left(\mathrm{S}_{\mathrm{gc}, 0}\right)$ is dependent on the conversion, char preparation, governing reaction conditions, chemical kinetics of reaction and presence of fragmentation during reduction. $\mathrm{S}_{\mathrm{gc}, 0}$ do not exhibit a

10 significant increase as conversion progresses under Zone II burning regime, a condition when external diffusion and chemical reaction rates are nearly identical [18, 19]. As a result, a constant structural parameter $(\varphi)$ value equal to 2 is selected to provide a moderate increase in specific surface area per unit mass. When dealing with the effective diffusion $\left(\mathrm{D}_{\text {eff }}\right)$ of the oxidant, the bulk and Knudsen diffusion contributions

15 on the mass transport rate of oxidants within the porous structure of a burning char particle is considered [20].

The effectiveness factor $(\eta)$ represents the extent at which external chemical reaction rates are affected by pore diffusion, equation (8) [16].

$\eta=\frac{3}{\varnothing}\left(\frac{1}{\tanh \varnothing}-\frac{1}{\varnothing}\right)$ Eq. 8

20 Effectiveness factor is the ratio of observed or actual chemical reaction rate to maximum possible chemical reaction rate without internal diffusion control. Because the rate of chemical reaction is a function of the rate of consumption of $\mathrm{O}_{2}$, this definition can also be stated as the ratio of actual consumption of $\mathrm{O}_{2}$ to maximum consumption of $\mathrm{O}_{2}$ without internal diffusion control. When the value of effectiveness

25 factors is nearly equal to one, the observed chemical reactions and the maximum possible chemical reaction are identical. 
The average initial density of sample char particles used was $451 \mathrm{~kg} / \mathrm{m}^{3}$. Char porosities were calculated based on the measured initial char density and the solid char density at $1950 \mathrm{~kg} / \mathrm{m}^{3}$ [21]. Based on a one kilogram char particle basis, two possible mechanisms can occur with $\mathrm{O}_{2}$ oxidant. The stoichiometric coefficients $(v)$ in equation

5 (6) can be either 2.667 for combustion or 1.333 for gasification. For this study under combustion the stoichiometric coefficient is 2.667 . The initial specific surface area for oakwood char was taken as $400 \mathrm{~m}^{2} / \mathrm{g}$ [22]. Majority of experimental studies that use char specific surface areas are based on the BET method, which is a measure of the physical adsorption of gas molecules at the surfaces [23]. As a comparison to oakwood

10 char particles, the specific surface area of eucalyptus wood char measured using BET method $\left(\mathrm{N}_{2}\right.$ at $\left.77 \mathrm{~K}\right)$ was $387 \mathrm{~m}^{2} / \mathrm{g}$ [24].

\subsection{Char Particle Energy Conservation}

Although the char surface temperature $\left(T_{S}\right)$ is difficult to measure especially for the spherical particles as used in this experiment, this was calculated iteratively by 15 considering a simplified steady-state energy process. Char surface temperatures were calculated based on + or $-1 \%$ of the total energy released during combustion at every $5 \mathrm{sec}$ time increments. The energy flows at the particle surface couples the energy and mass transfers giving rise to the derivation of equation (9). This equation incorporates the energy losses that are released from the char surface via radiation. The gas phase

20 thermal conductivities and specific heat of air and $\mathrm{O}_{2}$ are varied based on calculated char surface temperature. The varying Lennard-Jones parameters with change in temperature were used to calculate the bulk and effective diffusion coefficients of prevailing gases generated during these reactions [13]. Under these considerations, equation (8) was derived and used to calculate the char surface temperature as follows

25 [13]:

$\dot{m}_{C} \Delta h_{C}=\dot{m}_{C} C_{p g}\left[\frac{\exp \left(-\frac{\dot{m}_{C} C_{p g}}{4 \pi k_{g} r}\right)}{1-\exp \left(-\frac{\dot{m}_{C} C_{p g}}{4 \pi k_{g} r}\right)}\right]\left(T_{S}-T_{\infty}\right)+\varepsilon_{S} 4 \pi r^{2} \sigma\left(T_{S}^{4}-T_{\infty}^{4}\right)$ 
A one-film kinetic-diffusion model was assumed since there was no flame in the gas phase and the maximum temperature occurs at the particle surface during combustion.

\subsection{Results and Discussion}

\section{$5 \quad 5.1$ Effect of $\mathrm{O}_{2}$ enrichment and initial temperature on conversion}

Normalized conversion plot and particle diameter results for the four cases studied here are provided in Figures 3A and 3, respectively for a total reaction time of $40 \mathrm{sec}$. As expected, the greatest char conversion is obtained under oxygen enriched air conditions, Test No. $4\left(850{ }^{\circ} \mathrm{C}\right.$ with $6 \mathrm{~m}^{3} / \mathrm{h}$ air and $\left.2 \mathrm{~m}^{3} / \mathrm{h} \mathrm{O}_{2}\right)$. As shown, $62 \%$

10 conversion was achieved with $\mathrm{O}_{2}$ enriched air as compared to $40 \%$ at same temperature (i.e., $850{ }^{\circ} \mathrm{C}$ ) with air only $\left(\right.$ at $6 \mathrm{~m}^{3} / \mathrm{h}$ ). Similarly, for the lower temperature case at 800 ${ }^{\circ} \mathrm{C}$, the conversion with $\mathrm{O}_{2}$ enriched air was $53 \%$, which is $20 \%$ greater than $33 \%$ for Test No.1 $\left(800{ }^{\circ} \mathrm{C}\right.$ with air only at $\left.6 \mathrm{~m}^{3} / \mathrm{h}\right)$. Correspondingly, as depicted in Figures 3B, for $\mathrm{D} / \mathrm{Do}$ ratios, there is a significant decrease with these values with enriched

15 conditions at identical temperatures. These experiments show that the effect of $\mathrm{O}_{2}$ enrichment with as low as $25 \%$ by volume have a significant contribution on the conversion and combustion rate of oakwood char particles as compared to a $50{ }^{\circ} \mathrm{C}$ rise in reactor temperature.

\subsection{Effect of O2 enrichment on char particle diameter}

20 Figure 4 (A) provides the images of oakwood spherical char particle initially at $0.075 \mathrm{~g}$ and reactor temperature at $800^{\circ} \mathrm{C}$ for air flow rate of $6 \mathrm{~m}^{3} / \mathrm{h}$. As reaction progresses with time, particle diameter decreases from the start of reaction towards the end. It is observed that the leftover char and ash slowly drop to the bottom of the stainless steel wire tethering device during combustion. Figures 4 (B), (C) and (D) provide the images

25 of oakwood spherical char particles for the other test number cases, see Table 1. $\mathbf{5 . 3}$

Characterization of diffusional rate relationships via the ASCM, RPM and Thiele analysis 
Table 2 provides a summary of the linear fit estimated apparent kinetic parameters (i.e., activation energy and frequency factor). Higher temperatures and oxygen enriched air conditions provided lower activation energies $\left(\mathrm{E}_{\mathrm{a}}\right)$ and frequency factors (i.e., A and $\mathrm{k}_{\mathrm{o}}$ ) than normal air case. The ASCM method provided kinetic

5 parameters with reasonable consistency, i.e., the activation energy was inversely proportional to reactivity (oxygen enriched air condition). However, this is not the case for the RPM except when using air combustion only. The reason behind this is the fact that the combustion regime is influenced by diffusional effects inside the char. According to Murphy and Shaddix [25], inter-particle variations in reactivity may

10 scatter burning rates during diffusion controlled conditions. However, this condition also occurs for single large particles during combustion. Overall, it was observed that the ASCM is relatively consistent in obtaining apparent kinetic parameters for large particles that operate near kinetic-diffusion controlled (i.e. $\mathrm{R}_{\mathrm{kin}} / \mathrm{R}_{\mathrm{diff}} \sim 1$ or Zone II) combustion regimes. The RPM also assumes that $100 \%$ of the reduction is fully kinetic

15 at the pores and that diffusion rate is negligible, which is not the case which will be shown later with the Thiele analysis. Also, the RPM was developed to characterize the internal char reductions of very small particles in the micrometer range. Conversely, the values obtained with the ASCM provide a better insight of the actual activation energies for large particles. Some researchers claimed that external diffusion tends to

20 influence combustion of large particles, greater than $1.5 \mathrm{~mm}$ in geometric size [26]. This implies that during the combustion period, the heat generated is contained within the vicinity of the particle's external surface, causing more carbon combustion rates to occur at the surface than inside of the porous particle. As shown in Table 2, the highest activation energy value obtained was $180 \mathrm{~kJ} / \mathrm{mol}$ using the ASCM. The lowest 25 activation energy of the reaction $(123 \mathrm{~kJ} / \mathrm{mol})$ was achieved at higher temperature of $850{ }^{\circ} \mathrm{C}$ with $6 \mathrm{~m}^{3} / \mathrm{h}$ air and $2 \mathrm{~m}^{3} / \mathrm{h} \mathrm{O}_{2}$. As expected $\mathrm{O}_{2}$ enriched conditions and higher reactor temperatures provide less activation energy as compared with no $\mathrm{O}_{2}$ enrichment of air and lower reactor temperatures. 


\subsection{Effects of combustion parameters on activation energies}

Table 3 provides the relationships of the apparent activation energies to the average ratio of resistances of kinetic-to-diffusion rates ( $\left.\mathrm{R}_{\text {kin }} / \mathrm{R}_{\text {diff }}\right)$, effectiveness factors (n) and Thiele modulus. The lower activation energy (i.e., high reactivity) provided higher values of Thiele modulus (Ø) and lower values of effectiveness factip)ts ( Thiele modulus values are favorable at higher temperatures and $\mathrm{O}_{2}$ enriched air reactions under identical oxidation conditions. This indicates that the external chemical reaction rates are faster at higher temperatures and $\mathrm{O}_{2}$ enriched conditions than pore diffusion rates.

\section{$10 \quad 6.0$ Error and Uncertainty Estimates}

To reduce random errors, the experimental facility was mounted on a resilient rubber material to mitigate and absorb external weight disturbances. The weighing scale top surface was also sufficiently shielded to eliminate fluid force effects from space air conditioning diffusers. Thermocouples and weighing scale that are used in the

15 experiments were calibrated to determine systematic errors. The weighing scale can precisely measure up to 0.001 gram and zero setting was set before proceeding with the experiments. The estimated total percent error of calibration and measurement for the weighing scale is $0.15 \%$. Because of the lack of knowledge about the exact value of weight measurements, nonlinear regression curve fit values were used as a reference

20 point in calculating maximum and average errors. The maximum weight error estimated is shown in Figure 5. The results shown in Table 4, reveals that higher reactor temperature $\left(850^{\circ} \mathrm{C}\right)$ provided higher greater average and maximum errors as compared to that at lower temperature of $800^{\circ} \mathrm{C}$ and these errors are attributed to fluid dynamic effects.. These errors are significantly greater than measurement and calibration errors 25 at $0.15 \%$, indicating a significant presence of random errors as also observed in past studies [27]. Random error owing to electronic noises is not a major issue because variable frequency drives and logic circuits were not used in these experiments. Therefore, random errors were mainly attributed to system environmental factors such 
as system internal vibrations and fluid dynamic effects on weight measurements due to temperature and flow variations (see Table 4). The thermocouples have a combined measurement and scaling error of $\pm 5.0^{\circ} \mathrm{C}$. The thermocouple sensing elements were cleaned periodically and most of the measurements are very stable. Hence, there are significantly less noticeable random errors on temperature measurements as compared to weight measurements.

\subsection{Conclusions}

The combustion regimes of large spherical char particles between 6.7 to 6.9 $\mathrm{mm}$ have been investigated with $\mathrm{O}_{2}$ enriched air at 800 and $850{ }^{\circ} \mathrm{C}$ under atmospheric conditions for up to 40 second reaction time. Experimental and numerical results using two models and Thiele analysis provides the following conclusions:

a. The effect of $\mathrm{O}_{2}$ enriched air with as low as $25 \%$ by mole fraction has more significant contribution on large wood char particle conversion as compared to a $50{ }^{\circ} \mathrm{C}$ rise in reactor temperature.

15 b. Higher temperatures and oxygen enriched air conditions provided lower activation energies $\left(E_{a}\right)$ and frequency factors (i.e., $A$ and $k_{o}$ ) than none enriched conditions.

c. The ASCM method provided kinetic parameters with reasonable consistency, i.e. the activation energy is inversely proportional to higher reactivity (oxygen enriched air conditions).

d. The highest activation energy value was obtained at $180 \mathrm{~kJ} / \mathrm{mol}$ and the lowest activation energy of the reaction $(123 \mathrm{~kJ} / \mathrm{mol})$ was achieved at higher temperature of $850{ }^{\circ} \mathrm{C}$ with $6 \mathrm{~m}^{3} / \mathrm{h}$ air and $2 \mathrm{~m}^{3} / \mathrm{h} \mathrm{O}_{2}$ using the ASCM.

e. Thiele modulus values are favorable at higher temperatures and $\mathrm{O}_{2}$ enriched air reactions under identical oxidation conditions. This indicates that the external chemical reaction rates are faster for higher temperatures and $\mathrm{O}_{2}$ enriched conditions than pore diffusion rates. 


\subsection{Acknowledgments}

The support provided by ONR and US Navy is gratefully acknowledged.

\subsection{Nomenclature}

A

5

$c_{\mathrm{p}}$

$\mathrm{C}$

$\mathrm{D}$

dt

$\varepsilon_{\mathrm{S}}$

10

$\mathrm{E}_{\mathrm{a}}$

$\eta$

$\mathrm{k}$

$\mathrm{k}_{\mathrm{o}}$

$\mathrm{L}$

15

$\Theta$

$\dot{m}_{C}$

$\ddot{m}_{C}$

$\mathrm{MW}_{\text {mix }}$

$\mathrm{MW}_{\text {ox }}$

$20 \quad P$

$\rho$

r frequency factor, $\mathrm{m} / \mathrm{s}$

constant pressure specific heat

carbon

diffusion coefficient of oxidant and gas product

time step

emissivity

activation energy, $\mathrm{kJ} / \mathrm{mol}$

effectiveness factor

conductivity

random pore model frequency factor

the equivalent length of overlapping pores per unit char volume

char porosity

time rate of change of char weight

mass flux of char particle

combined molecular weight of oxidant and gas product

molecular weight of oxidant

partial pressure of molecular weight

density of oxidant

particle radius 


\begin{tabular}{|c|c|c|}
\hline \multicolumn{2}{|c|}{$\mathrm{R}_{\mathrm{u}}$} & molar gas constant \\
\hline & $\mathrm{R}$ & resistance \\
\hline & $\operatorname{Re}$ & Reynolds number \\
\hline & $\sigma$ & Stefan-Boltzman constant \\
\hline 5 & $\varphi$ & structural parameter \\
\hline \multirow{9}{*}{10} & $\mathrm{~S}_{\mathrm{gc}}$ & char specific surface area \\
\hline & $\mathrm{T}$ & temperature \\
\hline & $v$ & stoichiometric coefficient \\
\hline & $\mathrm{W}$ & weight \\
\hline & $\Delta \mathrm{W}$ & $\mathrm{W}_{0}-\mathrm{W}_{\mathrm{f}}$ \\
\hline & $\mathrm{dX} / \mathrm{dt}$ & char conversion rate \\
\hline & $\mathrm{X}$ & char mass conversion based on dry and ash free particles, $\left(1-\mathrm{W} / \mathrm{W}_{0}\right)$ \\
\hline & $Y_{o x, \infty}$ & oxidant mass fraction at the far field \\
\hline & $\mathrm{Y}_{\mathrm{ox}, \mathrm{s}}$ & oxidant mass fraction at particle surface \\
\hline 15 & $\varphi$ & structural parameter \\
\hline & $\varnothing$ & Thiele modulus \\
\hline
\end{tabular}

\subsection{Subscripts}

c char or carbon particle

diff diffusion

20 eff effective

f final

g gas 


$\begin{array}{lll} & \mathrm{k} & \text { time marching } \\ & \text { kin } & \text { kinetic } \\ & 0 & \text { initial conditions } \\ & \text { ox } & \text { oxidant } \\ & \text { s } & \text { surface location } \\ & \text { sur } & \text { surroundings } \\ & & \text { farfield location }\end{array}$

\subsection{References}

[1] Foundation for the Future, "Energy Challenges: The Next Thousand Years" April 102007.

[2] Worley, M. and Yale, J., "Biomass Gasification Technology Assessment", National Renewable Energy Laboratory, U.S. Department of Energy, Nov. 2012.

[3] Luckow, P., Dooley, J. J., Wise, M. A., and Kim, S. H., "Biomass Energy for Transport and Electricity: Large Scale Utilization Under Low $\mathrm{CO}_{2}$ Concentration 15 Scenarios”, U.S. Department of Energy, Jan 2010.

[4] Kaldas, A., Carabin, P., Chevalier, P., Chronopoulos, C., Picard, I., Alexander, G., Mann, J., Molintas, H., Spezio, J. and Holcroft, G., "Plasma Arc Waste Destruction System (PAWDS): A Novel Approach to Waste Elimination Aboard Ships", Naval Engineers Journal, Vol. 118, No. 3, 2006, pp. 139-150.

20 [5] Williams, A., Pourkashanian, M. and Jones, J. M., "Combustion of Coal and Biomass”, Progress in Energy and Combustion Science, Vol. 27, No.6, 2001, pp. 587610.

[6] Yang, Y. B., Sharifi, V. N., Swithenbank, J., Ma, L., and Darvell, L., “Combustion of a Single Particle of Biomass”, Vol. 22, No.1, Energy \& Fuels 2008, pp. 306-316. 
[7] Lu, H., Robert, W., Peirce, G., Ripa, B. and Baxter, L., "Comprehensive Study of Biomass Particle Combustion”, Energy and Fuels, No. 22, 2008, pp. 2826-2839.

[8] Kouchaksaraeia, M., "Fundamental Study of Single Biomass Particle Combustion", Aalborg University, PhD Dissertation, 2013.

5 [9] Wen, W. and Cain E., "Catalytic Pyrolysis of a Coal Tar in a Fixed Bed Reactor", Industrial Engineering Chemical Process Design and Development, No. 23, 1984, pp. $627-637$.

[10] Sangtong-Ngam K., and Narasingha M., "Kinetic Study of Thai-lignite Char Gasification Using the Random Pore Model”, Thammasat Intl. J. Science Technology, 10 Vol. 13, No. 3, 2008, pp. $16-26$.

[11] Herzberg, M.; Zlochower, I. A.; Edwards J. C. Coal particle pyrolysis mechanisms and temperatures; Report RI 9169, Bureau of Mines: Springfield,VA, 1988.

[12] Bryden, K. M.; Hagge, M. J., "Modeling the Combined Impact of Moisture and Char Shrinkage on the Pyrolysis of a Biomass Particle”, Fuel 2003, Vol. 82, No. 13, pp. $15 \quad 1633-1644$.

[13] Turns S. R., “An Introduction to Combustion”, McGraw Hill Book Co., Second Edition, 2000, pp. 656-658.

[14] Gomez-Serrano, V., Valenzuela-Calahorro, C. and Pastor-Villegas, J., "Characterization of Rockrose Wood, Char and Activated Carbon", Biomass and 20 Bioenergy Vol. 4 , No. 5, 1993, pp. 355-364.

[15] Bhatia, S. K. and Perlmutter, D. D., "A Random Pore Model for Fluid-Solid Reactions: Isothermal, Kinetic Control,” AIChE J., 26, 1980, pp.379-386.

[16] Thiele, E.W., "Relation Between Catalytic Activity and Size of Particle”, Ind. Eng. Chem., Vol. 31, No. 7, 1939, pp. 916-920.

25 [17] Harris, D., Roberts, D., and Hia, S., "CFD Modeling for an Entrained Flow Gasification Reactor Using Measured Intrinsic Kinetic Data”, Fifth International Conference on CFD in the Process Industries, Melbourne, Australia, Dec. 2006. 
[18] Jankowska, H., Swiatkowski, A., Choma, J. and Ellis, H., “Active Carbon”, Prentice-Hall, Englewood Cliffs, NJ, 1991.

[19] Hurt, R. H., Sarofim, A. F. and Longwell, J. P., "Role of Microporous Surface Area in Uncatalyzed Carbon Gasification," Energy and Fuels, Vol. 5, No. 2, 1991, pp. $5 \quad 290-299$.

[20] Satterfield, C. N., Mass Transfer in Heterogeneous Catalysis, MIT Press, Cambridge, 1970.

[21] Lide, D.R., "Handbook of Chemistry and Physics", CRC Press, Eighty-Sixth Edition, 2005, pp. 229-233.

10 [22] Pastor-Villegas, J., Pastor-Valle, J. F., Meneses Rodriguez, J. M., and Garcia, M. G., "Study of Commercial Wood Charcoals for the Preparation of Carbon Adsorbents", Journal Analysis of Applied Pyrolysis, Vol. 76, Issues 1-2, 2006, pp. 103-108.

[23] S. Brunauer, P. H. Emmett and E. Teller, J. Am. Chem. Soc., 1938, 60, 309.

[24] Lin, L., Gustafsson, E. and Strand, M., "High Temperature Kinetics of Fine

15 Biomass Char Particles in Air and CO2”, 18th European Biomass Conference and Exhibition, Lyon, France, Jan. 2010.

[25] Murphy, J. J. and Shaddix, C. R. "Combustion Kinetics of Coal Chars in OxygenEnriched Environments", Combustion and Flame, Vol. 144, No. 4, 2006, pp. 710-729. [26] Dennis, J.S., Hayhurst, A. N. and Scott, S.A., " The combustion of large particles 20 of char in bubbling fluidized beds: The dependence of Sherwood number and the rate of burning on particle diameter", Combustion and Flame, Vol. 147, No. 3, 2006, pp. 185194.

[27] Molintas, H. and Gupta, A.K., "Kinetics of Char Reduction of Residual Char Particles Using Air and O2", Applied Energy Journal, Vol. 88, No. 1, January 2011, pp. $25 \quad 306-315$. 


\section{List of Figures and Tables}

\section{List of Figures}

Fig. 1. (a) Raw spherical Oakwood with average weight of $0.48 \mathrm{~g}$ and (b) Spherical Oakwood char particle weighing between $0.075 \mathrm{~g}$ to $0.081 \mathrm{~g}$

Fig. 2. A schematic diagram of the experimental facility

Fig. 3. Combustion results of large spherical char particles

Fig. 4. Images of spherical char particles taken every $5 \mathrm{sec}$ time intervals (Tests 1, 23 and 4)

Fig. 5. Maximum error bars for weight with time at $800^{\circ} \mathrm{C}$

\section{List of Tables}

Table 1. Test matrix used in the investigation

Table 2. Summary of the linear fit derived kinetic parameters

Table 3. Relationships of the activation energy with other reduction parameters

Table 4. Estimated weight errors (percent) 

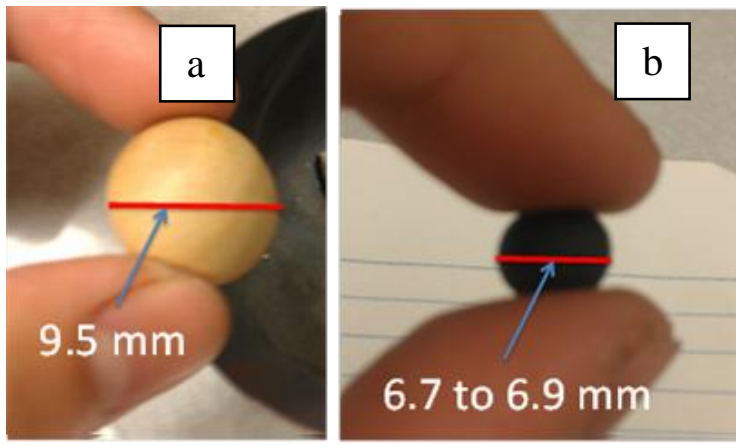

Fig. 1. (a) Raw spherical oakwood with average weight of $0.48 \mathrm{~g}$ and (b) Spherical oakwood char particle weighing between $0.075 \mathrm{~g}$ to $0.081 \mathrm{~g}$ 


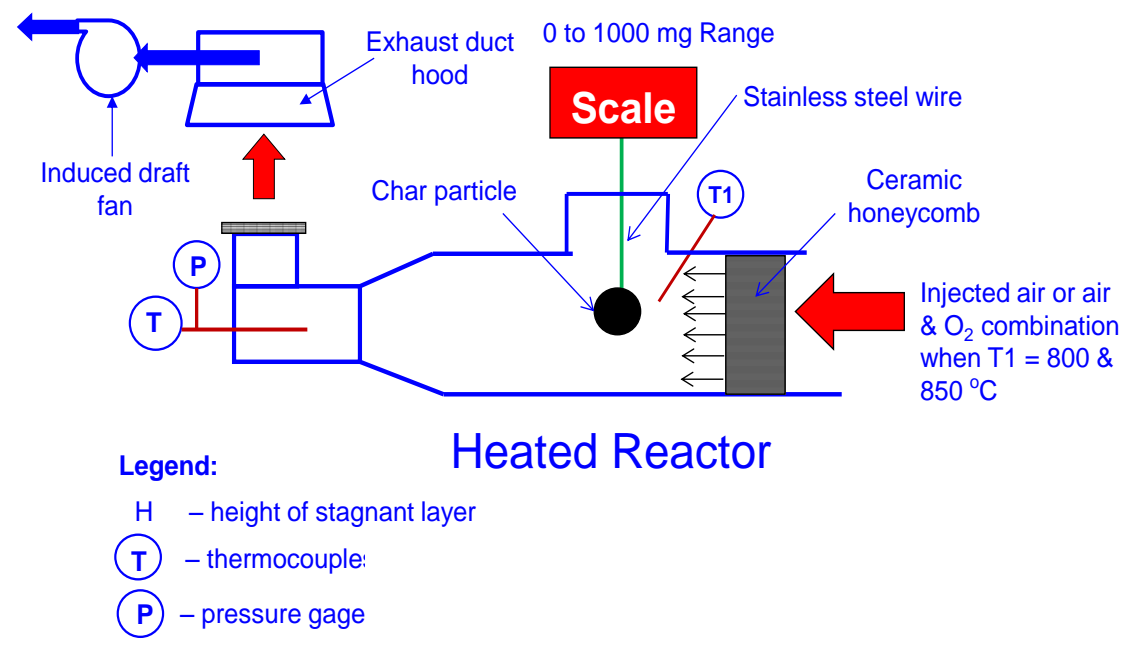

Fig. 2. Schematic diagram of the experimental facility 


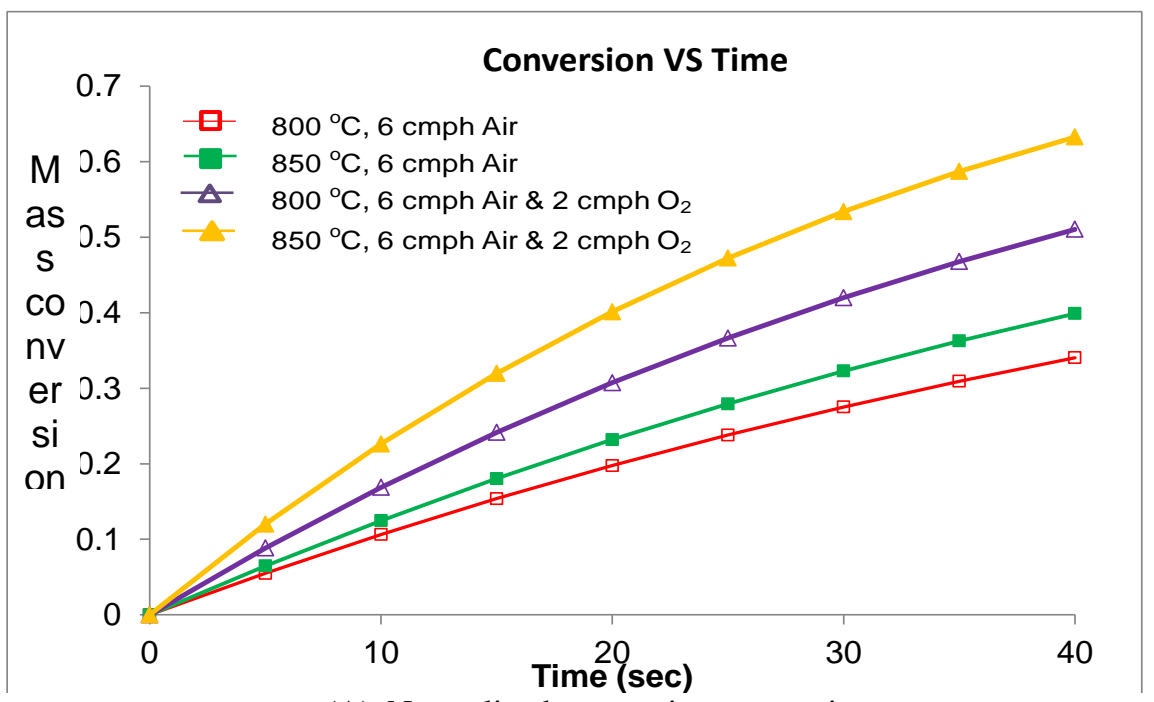

(A) Normalized conversion versus time

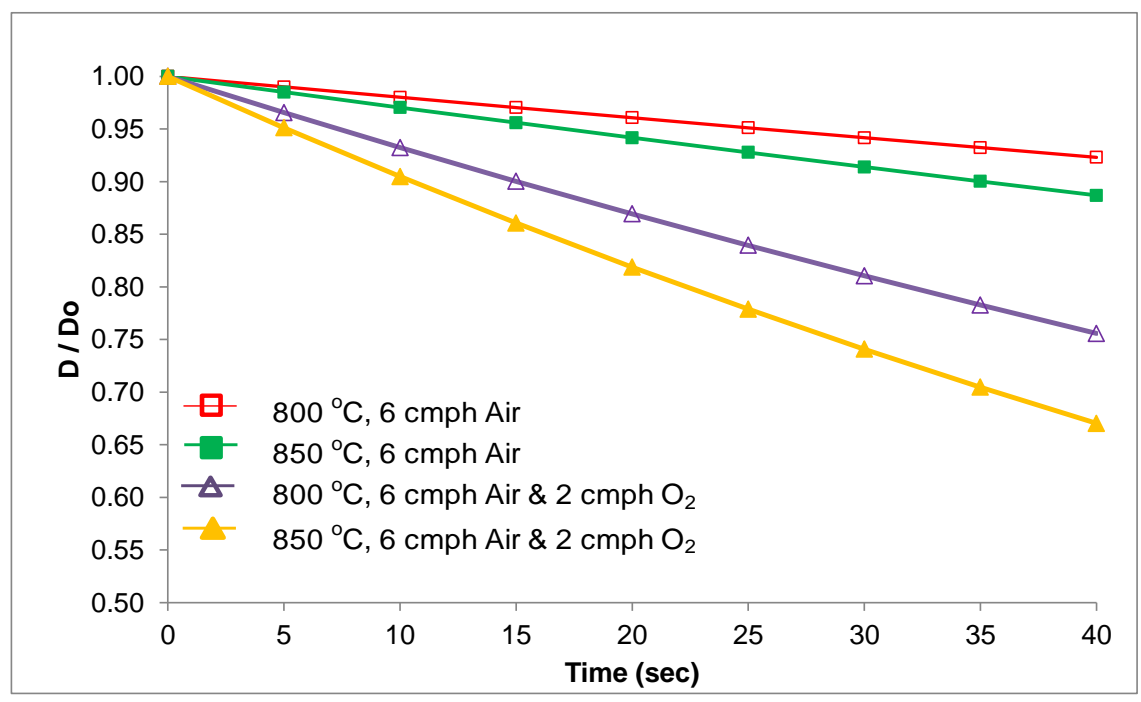

(B) Normalized particle diameter versus time

Fig. 3. Combustion results of large spherical char particles 


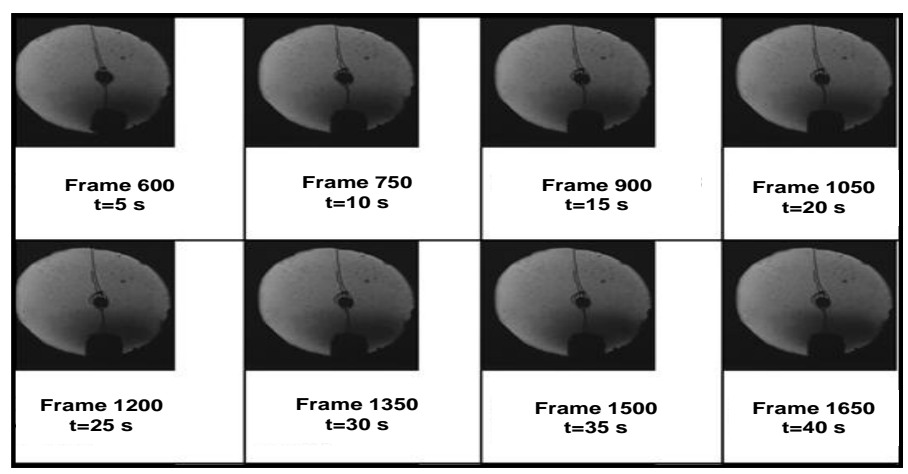

Test No. 1 (A)

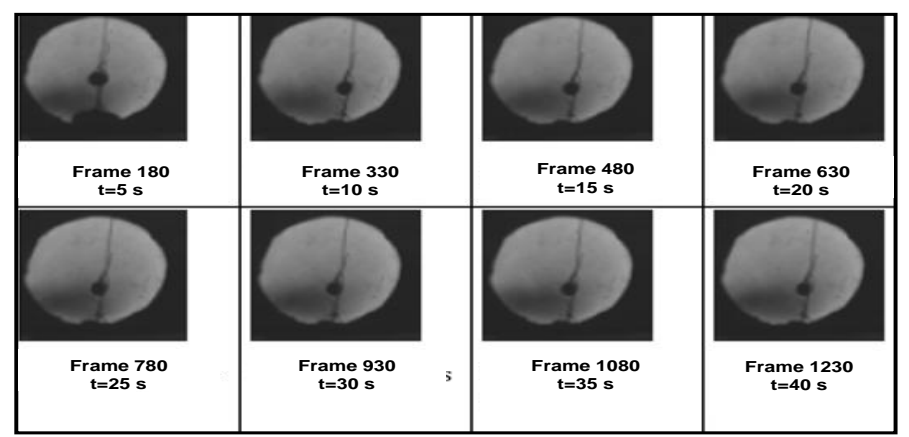

Test No. 2 (B)

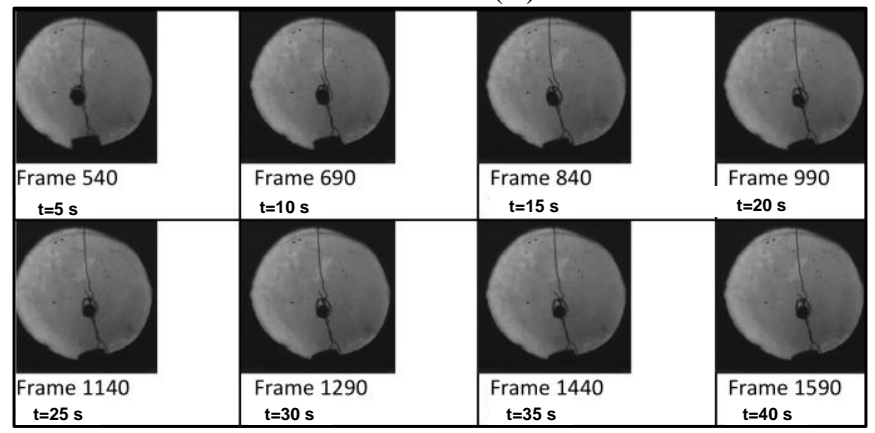

Test No. $3(\mathrm{C})$

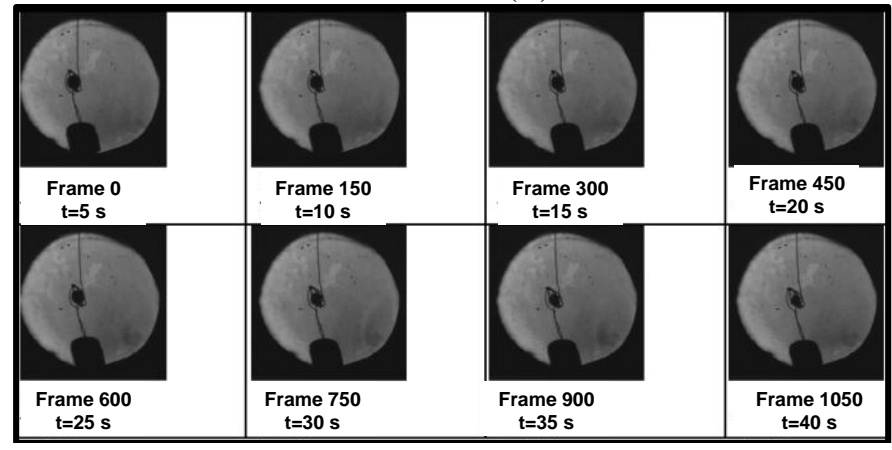

Test No. 4 (D)

Fig. 4. Five second images of spherical char particles (Test Nos. 1, 23 and 4) 


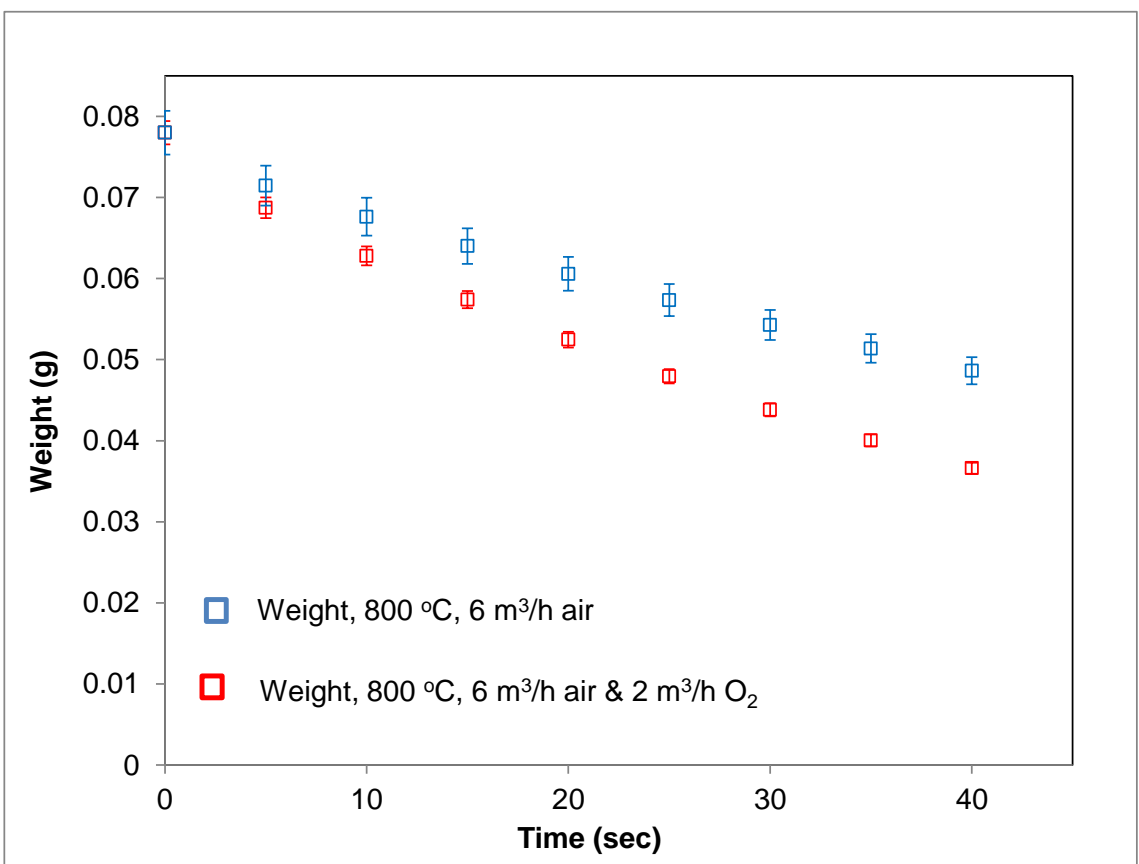

Fig. 5. Maximum weight error bars with time at $8^{\circ} 0^{\circ} \mathrm{C}$ 
Table 1. Test matrix used in the investigation

\begin{tabular}{|c|c|c|c|c|c|c|}
\hline Test No. & $\begin{array}{c}\text { Weight } \\
(\mathrm{g})\end{array}$ & $\begin{array}{c}\text { Temp } \\
\left({ }^{\circ} \mathrm{C}\right)\end{array}$ & $\begin{array}{c}\text { Diameter } \\
(\mathrm{mm})\end{array}$ & $\begin{array}{c}\text { Air Flow } \\
\left(\mathrm{m}^{3} / \mathrm{h}\right)\end{array}$ & $\begin{array}{c}\mathrm{O}_{2} \text { flow } \\
\left(\mathrm{m}^{3} / \mathrm{h}\right)\end{array}$ & Re \\
\hline 1 & 0.075 & 800 & 6.7 & 6 & & 51 \\
\hline 2 & 0.075 & 850 & 6.7 & 6 & & 50 \\
\hline 3 & 0.076 & 800 & 6.8 & 6 & 2 & 38 \\
\hline 4 & 0.078 & 850 & 6.8 & 6 & 2 & 37 \\
\hline
\end{tabular}


Table 2. Summary of the linear fit derived kinetic parameters

\begin{tabular}{|c|c|c|c|c|c|c|c|c|c|}
\hline Test No. & $\begin{array}{c}\text { Temp } \\
\left({ }^{\circ} \mathrm{C}\right)\end{array}$ & $\begin{array}{c}\text { Air } \\
(\mathrm{cmph})\end{array}$ & $\begin{array}{c}\mathrm{O}_{2} \\
(\mathrm{cmph})\end{array}$ & $\begin{array}{c}\mathrm{Ea} \\
(\mathrm{ASCM}), \\
\mathrm{kJ} / \mathrm{mol}\end{array}$ & $\begin{array}{c}\mathrm{A} \\
(\mathrm{ASCM}), \\
\mathrm{m} / \mathrm{s}\end{array}$ & $\begin{array}{c}\mathrm{Ea}(\mathrm{RPM}), \\
\mathrm{kJ} / \mathrm{mol}\end{array}$ & $\begin{array}{c}\mathrm{k}_{\mathrm{o}}(\mathrm{RPM}), \\
1 / \mathrm{s}\end{array}$ & $\begin{array}{c}\text { Ea } / \Delta \mathrm{W} \\
(\mathrm{ASCM}), \\
\mathrm{kJ} / \mathrm{kg}- \\
\mathrm{mol}\end{array}$ & $\begin{array}{c}\mathrm{Ea} / \Delta \mathrm{W} \\
(\mathrm{RPM}), \\
\mathrm{kJ} / \mathrm{kg}- \\
\mathrm{mol}\end{array}$ \\
\hline 1 & 800 & 6 & & 180 & $2.13 \mathrm{E}+06$ & 128.0 & $8.34 \mathrm{E}+02$ & 6.90 & 4.91 \\
\hline 2 & 850 & 6 & & 163 & $1.00 \mathrm{E}+05$ & 114.2 & $1.11 \mathrm{E}+02$ & 3.75 & 3.75 \\
\hline 3 & 800 & 6 & 2 & 166 & $2.82 \mathrm{E}+05$ & 97.6 & $2.58 \mathrm{E}+01$ & 4.27 & 2.57 \\
\hline 4 & 850 & 6 & 2 & 123 & $2.83 \mathrm{E}+03$ & 142.8 & $4.24 \mathrm{E}+02$ & 2.39 & 2.76 \\
\hline
\end{tabular}


Table 3. Relationships of the activation energy with other reduction parameters

\begin{tabular}{|c|c|c|c|c|c|}
\hline Cases & $\mathrm{R}_{\mathrm{kin}} / \mathrm{R}_{\text {diff }}$ (Average) & Thiele Modulus & $\mathrm{Ea}(\mathrm{kJ} / \mathrm{mol}), \mathrm{ASCM}$ & $\mathrm{T}_{\mathrm{S}}\left({ }^{\circ} \mathrm{C}\right)$ & $\eta$ \\
\hline $800^{\circ} \mathrm{C}, 6 \mathrm{~m}^{3} / \mathrm{h}$ Air & 1.87 & \begin{tabular}{|l|}
499 \\
\end{tabular} & 180 & 1066 & 0.006 \\
\hline $850^{\circ} \mathrm{C}, 6 \mathrm{~m}^{3} / \mathrm{h}$ Air & 1.38 & 866 & 163.3 & 1213 & 0.0035 \\
\hline $800^{\circ} \mathrm{C}, 6 \mathrm{~m}^{3} / \mathrm{h}$ Air $\& 2 \mathrm{~m}^{3} / \mathrm{h} \mathrm{O}_{2}$ & 2.4 & 595 & 166 & 1310 & 0.005 \\
\hline $850^{\circ} \mathrm{C}, 6 \mathrm{~m}^{3} / \mathrm{h}$ Air $\& 2 \mathrm{~m}^{3} / \mathrm{h} \mathrm{O}_{2}$ & 2 & 965 & 123 & 1433 & 0.0031 \\
\hline
\end{tabular}


Table 4. Estimated weight errors (percent)

\begin{tabular}{|c|c|c|c|c|c|c|c|}
\hline Test No. & $\operatorname{Temp}\left({ }^{\circ} \mathrm{C}\right)$ & $\operatorname{Air}\left(\mathrm{m}^{3} / \mathrm{h}\right)$ & $\begin{array}{c}\mathrm{O} 2 \\
\left(\mathrm{~m}^{3} / \mathrm{h}\right)\end{array}$ & $\begin{array}{l}\text { Average total error } \\
\text { due to instrument \& } \\
\text { calibration }\end{array}$ & $\begin{array}{l}\text { Average total error } \\
\text { due to vibrations \& } \\
\text { fluid dynamic effects }\end{array}$ & Average total error & $\begin{array}{c}\text { Maximum } \\
\text { error }\end{array}$ \\
\hline 1 & 800 & 6 & & 0.15 & 1.41 & 1.56 & 3.44 \\
\hline 2 & 850 & 6 & & 0.15 & 2.31 & 2.46 & 7.03 \\
\hline 3 & 800 & 6 & 2 & 0.15 & 0.71 & 0.86 & 1.85 \\
\hline 4 & 850 & 6 & 2 & 0.15 & 2.79 & 2.94 & 7.05 \\
\hline
\end{tabular}

